\title{
PRODUCCIÓN DE METANO IN VITRO EN MEZCLA DE GRAMÍNEAS-LEGUMINOSAS DEL TRÓPICO ALTO COLOMBIANO
}

\author{
IN VITRO METHANE PRODUCTION IN THE INCUBATION OF MIXTURES OF GRASSES \\ AND LEGUMES FROM COLOMBIAN HIGH-ALTITUDE AREAS
}

\author{
Vargas, J. ; Pabón, M. ${ }^{1}$ y Carulla, J. ${ }^{1 *}$
}

'Departamento de Producción Animal. Facultad de Medicina Veterinaria y de Zootecnia. Universidad Nacional de Colombia. Bogotá. *jecarullaf@unal.edu.co

\section{PalABRAS CLAVE ADICIONALES \\ Efecto invernadero. Pasturas. Sistemas pastoriles.}

\section{RESUMEN}

Se determinó la producción de metano in vitro para mezclas de gramíneas:leguminosas del trópico alto colombiano, utilizando la técnica de producción de gas. En dos lotes diferentes, se recogieron muestras de dos gramíneas, ryegrass (Lolium perenne) y kikuyo (Pennisetum clandestinum), y dos leguminosas, trébol blanco (Trifolium repens) y lotus grande (Lotus uliginosus). Se evaluaron cuatro mezclas de las gramíneas y las leguminosas: kikuyo y lotus, kikuyo y trébol blanco, ryegrass y lotus y ryegrass y trébol en tres proporciones diferentes de gramínea:leguminosa (90:10, 70:30 y 50:50). La concentración de metano en el gas se determinó por cromatografía de gases. Al aumentar las proporciones de leguminosas en la mezcla con el kikuyo, la producción de metano por unidad de materia seca degradada disminuyó hasta un $14 \%(p<0,05)$. Sin embargo, no se observaron diferencias cuando se mezclaron con el ryegrass. Para el lotus, una leguminosa tanífera, al aumentar su proporción en la mezcla se disminuyó la producción total de metano $(p<0,05)$ y su proporción en el gas independientemente de la gramínea base sugiriendo un efecto del lotus sobre las poblaciones metanogénicas.

\section{SUMMARY}

In vitro methane production was determined in mixtures of grasses and legumes of Colombian highlands were evaluated using the gas production technique. Samples of two grasses, ryegrass (Lolium perenne) and kikuyu (Pennisetum clandestinum), and two legumes, white clover

\author{
AdDitiONAL KEYWORDS \\ Grasslands. Grazing systems. Greenhouse gases.
}

(Trifolium repens) and big trefoil (Lotus uliginosus), from two different paddocks were harvested. The treatments were mixtures of kikuyu and lotus, kikuyu and white clover, ryegrass and lotus and ryegrass and clover in three different grass: legumes ratio (90:10, 70:30 and 50:50). The methane concentration in the gas was determined by gas chromatography. Methane production per unit of degraded dry matter decreased $14 \%$ $(p<0.05)$ when the proportions of legume increased associated with kikuyu. However, no differences were observed when legumes were mixed with ryegrass. When proportion of lotus, a tanniferous legume, increased total methane production decreased independently of grass suggesting an effect in methanogenic population.

\section{INTRODUCCIÓN}

La producción de metano entérico en los rumiantes representa una pérdida energética que varía entre el 5 y $7 \%$ de la energía bruta consumida (Johnson y Johnson, 1995). Adicionalmente, el metano es uno de los gases efecto invernadero que tiene un poder de calentamiento 28 veces mayor al dióxido de carbono y una vida media en la atmósfera de 12,4 años (IPCC, 2013). Los rumiantes contribuyen de manera significativa a la producción de metano (Gerber et al., 2013) por lo cual se requiere reducir las emisiones de metano para aumentar la eficiencia productiva y disminuir el impacto 


\section{VARGAS, PABÓNY CARULLA}

ambiental (Gerber et al., 2013).

Gran parte de la producción animal con rumiantes se hace bajo sistemas pastoriles donde los forrajes son la principal fuente de alimento (Niggli et al., 2009) por lo cual, entender cómo los factores asociados a la calidad de los forrajes influyen en la producción de metano por los rumiantes, es un aspecto crítico. La incorporación de leguminosas en una dieta basada en gramíneas ha resultado en aumentos en la productividad animal y en el mejoramiento del balance de $\mathrm{N}$ en sistemas pastoriles (Castro et al., 2008; Tiemman et al., 2008). El impacto de las leguminosas y de las diferencias entre especies forrajeras sobre la producción de metano ha sido poco estudiado (Vargas et al., 2013; Hess et al., 2003). Los estudios in vitro suministran información preliminar acerca de estos recursos y su potencial producción de metano en la fermentación entérica. Tekippe et al. (2013) y Hess et al. (2003) utilizando el sistema Rusitec y evaluando especies de trópico cálido, encontraron que las emisiones de metano aumentaron al incluir una leguminosa con bajas concentraciones de taninos condensados, pero disminuyeron cuando la leguminosa contenía una alta concentración de taninos. Según Carulla et al. ( 2005) la adición de alfalfa o trébol al ryegrass (Lolium perenne) aumenta in vivo la producción de metano por unidad de materia orgánica fermentada. Vargas et al. (2012) sugieren que la inclusión de leguminosas ha presentado una respuesta contradictoria entre los trabajos revisados. La hipótesis evaluada en este trabajo era que al reemplazar parcialmente una gramínea por una leguminosa con taninos (lotus) la producción de metano disminuiría mientras al adicionar una leguminosa sin taninos (trébol) se aumentarían las emisiones de metano in vitro.

\section{MATERIAL Y MÉTODOS}

Se recogieron muestras de dos gramíneas, ryegrass (Lolium perenne) y kikuyo
(Pennisetum clandestinum), y dos leguminosas, trébol blanco (Trifolium repens) y lotus grande (Lotus uliginosus) en la estación Corpoica-Tibaitatá $\left(4^{\circ} 40^{\prime} 89^{\prime \prime} \mathrm{N}, 74^{\circ} 13^{\prime}\right.$ 13"W; 2540 msnm) en Colombia. Cada gramínea o leguminosa se recogió en dos lugares diferentes (lotes) con el fin de garantizar una repetición para cada especie. El ryegrass fue cosechado a los 35 días y el kikuyo, el trébol y el lotus a los 45 días de rebrote. Las muestras de los forrajes fueron congeladas a $-20^{\circ} \mathrm{C}$, liofilizadas y molidas en un molino de cuchillas (Romer®) con criba de $1 \mathrm{~mm}$. Se evaluaron cuatro mezclas de las gramíneas y las leguminosas: kikuyo y lotus, kikuyo y trébol blanco, ryegrass y lotus y ryegrass y trébol blanco en tres proporciones diferentes de gramínea:leguminosa (90:10, 70:30 y 50:50) para un total de 12 tratamientos.

Se empleó el procedimiento de incubación in vitro descrito por Pell y Scofield (1993) y adaptado por Parra y Ávila (2010). El fluido ruminal se obtuvo de un bovino fistulado en ayunas que pastaba kikuyo. El fluido fue filtrado a través de cuatro capas de gasa y gaseado con $\mathrm{CO}_{2}$. Se pesaron 0,1 $\mathrm{g}$ de forraje en botellas de $60 \mathrm{~mL}$, provistas de tapones de caucho de butilo y agrafes, y en cada botella se adicionaron $8 \mathrm{~mL}$ de buffer (pH 6,5; Goering y Van Soest, 1970) y $2 \mathrm{~mL}$ de fluido ruminal manteniendo un gaseado continuo con $\mathrm{CO}_{2}$. Las mezclas de los forrajes de cada uno de los dos lotes y un blanco ( $\sin$ forrajes) fueron incubadas por triplicado en una incubadora (Heidolph Titramax 1000) durante $48 \mathrm{~h}$ manteniendo una temperatura de $39^{\circ} \mathrm{C}$ y agitación suave. Finalizada la fermentación, se determinó el pH del contenido utilizando un potenciómetro (Hanna HI 98140), y se tomaron $2 \mathrm{~mL}$ del sobrenadante, que se acidificaron con $200 \mu \mathrm{l}$ de ácido sulfúrico concentrado al 98 $\%$ y se congelaron a $-20^{\circ} \mathrm{C}$ para el posterior análisis de ácidos grasos volátiles (AGVs). El contenido restante del tubo se filtró a través de bolsas de filtro F57 Ankom ${ }^{\circledR}$.

La producción de gas se cuantificó a las $0,2,4,8,12,18,24$ y 48 horas empleando un 


\section{PRODUCCIÓN DE METANO IN VITROEN MEZCLAS GRAMÍNEAS-LEGUMINOSAS}

medidor de presión manual (Bailey \& Mackey Ltda.; Theodorou et al., 1994). La producción total de gas fue la suma de las producciones a las horas de muestreo. Una muestra del gas producido a cada hora de muestreo fue conservada en vacutainers al vacío para posterior determinación de la concentración de metano.

En los forrajes y en los residuos de fermentación de cada botella, se determinó la materia seca (AOAC, 2005), para calcular la digestibilidad aparente de la materia seca (DMS), según lo descrito por Blümmel y Lebzien (2001). Adicionalmente, en los forrajes se determinó el contenido de nitrógeno por el método de Dumas (AOAC, 2005), de extracto etéreo (AOAC, 2005), de fibra en detergente ácido y neutro (Van Soest et al., 1991), de energía bruta por calorimetría (Parr® 6510) y el contenido de taninos condensados por el método de butanol-HCL (Terrill et al., 1992). Para determinar la concentración de metano en el gas producido a cada hora de muestreo y la concentración de AGVs del contenido de las botellas, se utilizó un cromatógrafo de gases (Shimadzu GC-2014) equipado con un detector de ionización de llama (FID), utilizando nitrógeno como gas de arrastre según lo descrito por Parra y Ávila (2010) y Betancourt (2001), respectivamente.

Se utilizó un diseño de bloques completos (dos lotes) con arreglo factorial $2 \times 2 \times 3$, dos gramíneas (ryegrass y kikuyo), dos leguminosas (trébol blanco y lotus) y tres proporciones (90:10, 70:30 y 50:50). Se utilizó el procedimiento ANOVA de SAS ${ }^{\circ}$ versión 9,2 para el análisis de varianza y las medias fueron comparadas con la prueba de Tukey con una significancia $5 \%$.

\section{RESULTADOS}

Las leguminosas presentaron un mayor contenido de energía, proteína bruta (PB), carbohidratos no estructurales (CNE) y lignina (LIG) que las gramíneas. Las gramíneas presentaron una mayor concen- tración de carbohidratos asociados a la pared. El lotus presentó el mayor contenido de taninos condensados (tabla I).

El pH del contenido de las botellas a las $48 \mathrm{~h}$ de incubación no presentó diferencias asociadas a la inclusión de leguminosas a las gramíneas. La producción de AGVs disminuyó $(\mathrm{p}<0,05)$ al incluir leguminosas en la mezcla y dependió de su nivel de inclusión (tabla II). Las proporciones molares de acetato fueron menores para el kikuyo que para el ryegrass mientras que las de propionato fueron mayores. La proporción de acetato cuando aumentó la proporción de leguminosa en la mezcla dependió de las especies mezcladas. El aumento en la proporción de lotus disminuyó la proporción de acetato $(\mathrm{p}<0,05)$ y no fue así para el trébol donde la concentración de acetato no cambió al aumentar su proporción en la mezcla.

Tabla I. Composición química (\% MS) de las especies evaluadas. (Chemical composition (\%DM) of evaluated species).

\begin{tabular}{lcccc}
\hline & Trébol & Lotus & Ryegrass & Kikuyo \\
\hline PB & 31,2 & 33,9 & 25,2 & 25,4 \\
EE & 5,52 & 2,15 & 4,13 & 5,07 \\
FDN & 30,8 & 31,6 & 46,5 & 48,3 \\
FDA & 15,9 & 20,6 & 25,5 & 22,5 \\
Hemicelulosa & 15,0 & 11,0 & 21,0 & 25,8 \\
Celulosa & 13,4 & 13,2 & 22,7 & 20,5 \\
Lignina & 2,48 & 7,29 & 2,80 & 1,97 \\
Carbohidratos & & & & \\
$\quad$ NE & 23,6 & 19,0 & 16,0 & 11,2 \\
totales & \\
Cenizas & 51,9 & 43,3 & 59,6 & 57,5 \\
TC & 8,54 & 9,16 & 8,32 & 10,05 \\
MO & 0,32 & 4,23 & 0,00 & 0,00 \\
Energía $^{3}$ & 91,5 & 90,8 & 91,7 & 90,0 \\
& 4,71 & 4,57 & 4,18 & 4,21 \\
\hline
\end{tabular}

$\mathrm{PB}=$ proteína bruta; $\mathrm{EE}=$ extracto etéreo; $\mathrm{FDN}=$ fibra detergente neutro; FDA = fibra detergente ácido; $\mathrm{NE}=$ no estructurales; $\mathrm{TC}=$ taninos condensados; $\mathrm{MO}=$ materia orgánica .

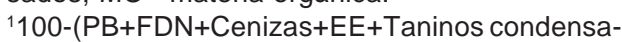
dos); ${ }^{2} \mathrm{FDN}+\mathrm{CNE}-\mathrm{Lig} ;{ }^{3} \mathrm{kcal} \mathrm{g}^{-1}$. 


\section{VARGAS, PABÓNYCARULLA}

La concentración de propionato fue mayor para las mezclas que contenían kikuyo comparativamente con aquellas que contenían ryegrass. La mayor inclusión de leguminosas en las mezclas aumentó las proporciones de propionato independientemente de la gramínea. Sin embargo, la adición de lotus al kikuyo tuvo un efecto mayor sobre las concentraciones de propionato que en el ryegrass. La proporción molar de butirato fue mayor para las combinaciones de kikuyo con trébol. Las mayores adiciones de leguminosas tendieron a aumentar las proporciones de butirato excepto en la mezcla de kikuyo y trébol blanco $(\mathrm{p}<0,05)$. La relación acetato:propionato presentó una interacción significativa entre tratamientos $(\mathrm{p}<0,05)$ (tabla II).

La adición de leguminosas a las gramíneas sobre la DMS dependió tanto de la especie de gramínea como de la leguminosa. En el caso del kikuyo la adición de trébol aumentó la DMS de la mezcla mientras que disminuyó con la adición de lotus $(\mathrm{p}<0,05)$. Para el ryegrass, la adición de trébol blanco no afectó la DMS de la mezcla mientras que la adición de lotus la disminuyó (tabla III). La producción total de gas fue similar entre

Tabla II. Efecto de la proporción $(P)$, gramínea $(G)$ : leguminosa $(L)$ sobre la fermentación ruminal in vitro. (Effect of proportion $(P)$ grass $(G)$ : legume $(L)$ on ruminal in vitro fermentation).

\begin{tabular}{|c|c|c|c|c|c|c|c|c|c|c|c|}
\hline & & & Rye & rass & G & L & P & $\mathrm{GxL}$ & LXP & GxP & LxGxP \\
\hline & Trébol & Lotus & Trébol & Lotus & & & & & & & \\
\hline $\mathrm{pH}$ & & & & & * & ** & $\mathrm{ns}$ & ns & + & ns & ns \\
\hline $90: 10$ & 6,60 & 6,65 & 6,68 & 6,66 & & & & & & & \\
\hline $70: 30$ & 6,62 & 6,64 & 6,69 & 6,68 & & & & & & & \\
\hline $50: 50$ & 6,63 & 6,64 & 6,68 & 6,68 & & & & & & & \\
\hline ÁGV (tot & $\mathrm{GV}(\mathrm{mmc}$ & & & & * & * & * & * & * & * & * \\
\hline $90: 10$ & $62,3^{\mathrm{a}}$ & $53,1^{a}$ & $63,7^{a}$ & 56,4 & & & & & & & \\
\hline $70: 30$ & $59,2^{\mathrm{ab}}$ & $35,4^{b}$ & $55,8^{b}$ & 52,8 & & & & & & & \\
\hline $50: 50$ & $54,7^{\mathrm{b}}$ & $30,6^{b}$ & $55,1^{b}$ & 54,2 & & & & & & & \\
\hline Acetato & $\%)$ & & & & * & * & * & * & ns & ns & ** \\
\hline $90: 10$ & 64,1 & $62,5^{\mathrm{a}}$ & 71,1 & $71,7^{a}$ & & & & & & & \\
\hline $70: 30$ & 64,7 & $59,6^{b}$ & 70,8 & $73,6^{a}$ & & & & & & & \\
\hline $50: 50$ & 63,1 & $58,6^{b}$ & 69,4 & $68,7^{b}$ & & & & & & & \\
\hline Propiona & nol \%) & & & & * & * & * & * & ns & ns & $\star *$ \\
\hline $90: 10$ & 27,4 & 32,0 & 22,8 & $22,3^{\mathrm{ab}}$ & & & & & & & \\
\hline $70: 30$ & 26,9 & 34,1 & 23,0 & $20,4^{b}$ & & & & & & & \\
\hline $50: 50$ & 28,9 & 34,8 & 23,7 & $23,7^{\mathrm{a}}$ & & & & & & & \\
\hline Butirato & $\%)$ & & & & * & * & ** & * & ns & ns & ns \\
\hline $90: 10$ & 8,5 & 5,5 & 6,2 & $6,0^{\mathrm{b}}$ & & & & & & & \\
\hline $70: 30$ & 8,5 & 6,3 & 6,3 & $6,0^{b}$ & & & & & & & \\
\hline $50: 50$ & 8 & 6,6 & 6,9 & $7,7^{\mathrm{a}}$ & & & & & & & \\
\hline Acetato: & ionato & & & & * & ** & * & * & ns & ns & $\star \star *$ \\
\hline $90: 10$ & 2,4 & 2,0 & 3,1 & $3,3^{a}$ & & & & & & & \\
\hline $70: 30$ & 2,4 & 1,8 & 3,1 & $3,7^{a}$ & & & & & & & \\
\hline $50: 50$ & 2,2 & 1,7 & 2,9 & $2,9^{b}$ & & & & & & & \\
\hline
\end{tabular}

${ }^{a b}$ Letras diferentes, diferencias significativas entre proporciones dentro de la asociación. ${ }^{*} p<0,01$; ${ }^{* *} p<0,05 ;{ }^{+} p<0,1 ; n s=$ no significativo. 
Tabla III. Efecto de la proporción $(P)$ gramínea $(G)$ : leguminosa $(L)$ sobre digestibilidad in vitro de la materia seca. (Effect of proportion $(\mathrm{P})$ grass $(\mathrm{G})$ : legume $(\mathrm{L})$ on in vitro digestibility of dry matter).

\begin{tabular}{|c|c|c|c|c|c|c|c|c|c|c|c|}
\hline & \multicolumn{2}{|c|}{ Kikuyo } & \multicolumn{2}{|c|}{ Ryegrass } & \multirow[t]{2}{*}{$\mathrm{G}$} & \multirow[t]{2}{*}{ L } & \multirow[t]{2}{*}{$\mathrm{P}$} & \multirow{2}{*}{$\mathrm{GxL}$} & \multirow{2}{*}{ LxP } & \multirow{2}{*}{ GxP } & \multirow{2}{*}{ LxGxP } \\
\hline & Trébol & Lotus & Trébol & Lotus & & & & & & & \\
\hline & & & & & * & * & ns & * & * & * & ns \\
\hline $90: 10$ & $63,6^{b}$ & $64,4^{a}$ & 67,6 & $64,8^{a}$ & & & & & & & \\
\hline 70:30 & $65,6^{b}$ & $63,6^{\mathrm{ab}}$ & 68,4 & $63,8^{a}$ & & & & & & & \\
\hline $50: 50$ & $68,4^{a}$ & $61,8^{b}$ & 68,3 & $60,4^{b}$ & & & & & & & \\
\hline
\end{tabular}

abLetras diferentes, diferencias significativas entre proporciones dentro de la asociación. ${ }^{*} p<0,01 ; n s$ : no significativo.

especies de gramínea y disminuyó con la adición de las leguminosas en el caso del kikuyo pero no del ryegrass. El efecto de la adición de leguminosas a las gramíneas sobre la producción de gas por unidad de materia seca degradada dependió de la especie de gramínea y de leguminosa. Para el kikuyo, al aumentar la inclusión de trébol disminuyó la producción de gas por unidad de materia seca degradada $(\mathrm{p}<0,05)$ mientras la adición de lotus no tuvo un efecto sobre este parámetro. En el caso de ryegrass, la producción de gas por unidad de materia seca degradada como consecuencia de la adición de trébol blanco no fue diferente mientras que la adición de lotus la incrementó (tablaIV).

La producción total de metano fue diferente entre especies de gramínea y disminuyó con la adición de las leguminosas excepto cuando se asoció el trébol y el ryegrass (tabla IV). La producción de metano por unidad de materia seca degradada dependió de la especie de gramínea y de leguminosa y fue mayor para las mezclas que contenían kikuyo que para aquellas que contenían ryegrass. Para el kikuyo, la producción de metano por unidad de materia seca degradada fue mayor cuando se adicionó trébol blanco que cuando se adicionó lotus $(\mathrm{p}<0,05)$. Al aumentar la proporción de trébol blanco o lotus, este parámetro disminuyó en el kikuyo mientras que no tuvo ningún efecto en el ryegrass (tabla IV). La relación metano:gas fue menor para el ryegrass que para el kikuyo $(\mathrm{p}<0,05)$. Para ambas gramíneas, el aumento en la proporción de trébol no tuvo ningún efecto mientras que la adición de lotus disminuyó esta relación (tabla IV).

\section{DISCUSIÓN}

La introducción de leguminosas en pasturas basadas en gramíneas ha sido promovida en muchos sistemas de producción de rumiantes debido al efecto positivo que tienen sobre el consumo de alimento y la producción animal (Castro et al., 2008; Tiemman et al., 2008). El impacto de estas prácticas debe considerar no solamente los aspectos productivos, sino incluir también aspectos ambientales (Beukes et al., 2009). Algunos trabajos han estudiado el efecto de adicionar una leguminosa a una gramínea en la producción de metano in vitro (Stürm et al., 2007; Hess et al., 2003) e in vivo (Lee et al., 2004; Woodward etal., 2004), pero las conclusiones que se pueden derivar de estos trabajos no son claras pues en algunos casos la adición de la leguminosa incrementa la producción de metano (Carulla et al., 2005) mientras en otros casos la disminuye (Lee et al., 2004). La diferencia en la producción de metano in vitro entre especies 
Tabla IV. Efecto de la proporción $(P)$ gramínea $(G)$ : leguminosa $(L)$ sobre la producción de gas, de metano y la relación metano:gas in vitro. (Effect of proportion $(\mathrm{P})$ grass $(\mathrm{G})$ : legume (L) on in vitro gas, methane and methane:gas ratio).

\begin{tabular}{|c|c|c|c|c|c|c|c|c|c|c|c|}
\hline & \multicolumn{2}{|c|}{ Kikuyo } & \multicolumn{2}{|c|}{ Ryegrass } & \multirow[t]{2}{*}{ G } & \multirow[t]{2}{*}{ L } & \multirow[t]{2}{*}{$\mathrm{P}$} & \multirow{2}{*}{ GxL } & \multirow{2}{*}{ LxP } & \multirow[t]{2}{*}{ GxP } & \multirow[t]{2}{*}{ LxGxP } \\
\hline & Trébol & Lotus & Trébol & Lotus & & & & & & & \\
\hline \multicolumn{12}{|c|}{ Producción de gas } \\
\hline$-m L$ & & & & & ns & * & ns & ns & * & * & ns \\
\hline $90: 10$ & $29,6^{a}$ & $27,7^{\mathrm{ab}}$ & 27,7 & 27,0 & & & & & & & \\
\hline $70: 30$ & $27,3^{b}$ & $28,0^{\mathrm{a}}$ & 28,0 & 27,5 & & & & & & & \\
\hline $50: 50$ & $27,3^{\mathrm{b}}$ & $26,2^{b}$ & 28,6 & 28,1 & & & & & & & \\
\hline \multicolumn{5}{|c|}{ - $\mathrm{mL} \mathrm{g}{ }^{-1} \mathrm{MS}$ degradada } & ** & * & ns & ** & * & * & ns \\
\hline 90:10 & $519,3^{\mathrm{a}}$ & 475,7 & 453,9 & $445,4^{b}$ & & & & & & & \\
\hline $70: 30$ & $463,2^{b}$ & 490,4 & 454,0 & $478,5^{b}$ & & & & & & & \\
\hline $50: 50$ & $446,9^{b}$ & 474,6 & 467,7 & $519,1^{a}$ & & & & & & & \\
\hline \multirow{2}{*}{\multicolumn{5}{|c|}{$\begin{array}{l}\text { Producción de metano } \\
-\mathrm{mL}\end{array}$}} & & & & & & & \\
\hline & & & & & * & * & * & * & * & * & * \\
\hline $90: 10$ & $3,44^{\mathrm{a}}$ & $3,14^{a}$ & $2,88^{b}$ & $2,75^{\mathrm{a}}$ & & & & & & & \\
\hline $70: 30$ & $3,17^{b}$ & $2,78^{b}$ & $3,04^{a}$ & $2,74^{a}$ & & & & & & & \\
\hline $50: 50$ & $3,19^{b}$ & $2,50^{c}$ & $2,98^{\mathrm{a}}$ & $2,60^{\mathrm{b}}$ & & & & & & & \\
\hline \multicolumn{5}{|c|}{ - $\mathrm{mL} \mathrm{g}^{-1} \mathrm{MS}$ degradada } & * & * & * & * & ns & * & * \\
\hline $90: 10$ & $61,0^{\mathrm{a}}$ & $53,6^{a}$ & 46,8 & 46,8 & & & & & & & \\
\hline $70: 30$ & $54,1^{\text {b }}$ & $48,8^{b}$ & 49,3 & 47,4 & & & & & & & \\
\hline $50: 50$ & $52,3^{b}$ & $45,5^{c}$ & 48,7 & 48,2 & & & & & & & \\
\hline \multicolumn{5}{|c|}{ Relación metano:gas } & * & * & * & * & * & $* *$ & ns \\
\hline $90: 10$ & 11,5 & $11,4^{\mathrm{a}}$ & 10,3 & $10,4^{\mathrm{a}}$ & & & & & & & \\
\hline $70: 30$ & 11,5 & $10,0^{\mathrm{b}}$ & 10,8 & $9,9^{a b}$ & & & & & & & \\
\hline $50: 50$ & 11,7 & $9,5^{b}$ & 10,2 & $9,1^{b}$ & & & & & & & \\
\hline
\end{tabular}

abLetras diferentes, diferencias significativas entre proporciones dentro de la asociación. ${ }^{*} \mathrm{p}<0,01$; ${ }^{* *} \mathrm{p}<0,05$; ns: no significativo.

forrajeras podría estar explicada por las diferencias en la proporción de carbohidratos digestibles en los forrajes y en la proporción de celulosa (Hess et al., 2003). En el presente trabajo se observó que el efecto de adicionar lotus al kikuyo o ryegrass era similar mientras que para el caso del trébol el efecto era diferente para cada una de estas gramíneas.

\section{ADICIÓN DE TRÉBOL A LAS GRAMÍNEAS Y PRODUCCIÓNDEMETANO}

Al aumentar la proporción de trébol en la mezcla con kikuyo, la producción de metano total y por unidad de materia seca degradada disminuyó, mientras que aumentó con el ryegrass. La adición de trébol al kikuyo o al ryegrass disminuyó la concentración de carbohidratos totales (4-5\%) debido a una menor concentración de éstos en la leguminosa. Adicionalmente, se observó una disminución en la concentración de AGV con la adición del trébol y una correlación lineal positiva entre los carbohidratos fermentados y la producción de AGVs $(r=0,74 ; p<0,01)$ sugiriendo una menor cantidad de carbohidratos fermentados a medida que se aumentó la proporción de la leguminosa en la mezcla, Vargas et al. (2013) encontraron que las producciones de gas y de metano in vitro estaban asociadas con la cantidad de carbohidratos fermentables y Van Soest 


\section{PRODUCCIÓN DE METANO IN VITROEN MEZCLAS GRAMÍNEAS-LEGUMINOSAS}

(1994) sugiere que esta fermentación está estrechamente asociada a la producción de AGVs, de gas y de metano. Por lo tanto, la menor producción de metano para la mezcla con kikuyo podría explicarse por una reducción en los carbohidratos fermentables, no así para la mezcla con ryegrass que a pesar de la reducción en los carbohidratos fermentables la producción de metano aumentó debido a la adición de trébol. Hess et al. (2003) encontraron un aumento en la producción de metano al adicionar una leguminosa a una gramínea tropical de baja calidad, este aumento se asoció a una mayor digestibilidad de la MS que podría aumentar la disponibilidad de los precursores de metano $\left(\mathrm{H}_{2}\right.$ y $\left.\mathrm{CO}_{2}\right)$. Otros autores también han asociado una mayor digestibilidad de la MS con una mayor producción de gas y de metano (Tavendale et al., 2005). Sin embargo, en el presente trabajo cuando se incrementó la proporción de trébol blanco en la mezcla con kikuyo se aumentó la digestibilidad de la MS pero no así la producción de metano, gas o AGVs, mientras en la mezcla con ryegrass, la adición de trébol aumentó la producción de metano sin modificar la digestibilidad de la MS.

En la mayoría de los casos, la adición de leguminosas a gramíneas aumenta la concentración de proteína cruda y disminuye la de carbohidratos totales en la mezcla (Hess et al., 2003). En nuestro trabajo, el aumento en la concentración de proteína entre la menor y la mayor inclusión de trébol al ryegrass o al kikuyo varió del 9 al $10 \%$, López (2005) sugiere que la producción de gas in vitro de sustratos altos en proteína no siempre está relacionada con la digestibilidad del material fermentado. La fermentación de las proteínas en el rumen puede resultar en la síntesis de proteína microbial, producción de amonio y/o AGVs, gas y metano. La proporción de cada uno de estos productos depende del tipo de proteína fermentada, las condiciones de fermentación, la disponibilidad de energía y los microorganismos involucrados (Leng, 2011).
En este trabajo, se presentó una relación inversa entre la producción de AGVs y la concentración de proteína en las mezclas $(r=-0,61 ; p<0,01)$. Sin embargo, el aumento en la concentración de proteína solo podría explicar la disminución en la producción de gas y de metano cuando se aumentó la proporción de trébol en las mezclas con kikuyo, ya que al aumentar los niveles de proteína debido a la adición de trébol al ryegrass, la producción total de gas no se modificó pero aumentó la de metano.

La diferencia en la respuesta en la producción de metano debida a la adición de trébol entre el kikuyo y el ryegrass podría explicarse por una diferencia en la síntesis de proteína microbial entre estas dos gramíneas. Blümmel et al. (1997) sugieren que los productos de la fermentación se distribuyen entre la producción de gas, síntesis de AGVs y de proteína microbial. Por lo tanto, un aumento en la síntesis de proteína microbial implicaría una disminución en la producción de gas y/o AGVs. En este mismo sentido, Hess et al. (2003) sugieren que la inclusión de niveles crecientes de una leguminosa con bajos contenidos de taninos aumenta la proporción de nitrógeno utilizado para la síntesis de proteína microbial. Se ha reportado en la literatura que una mayor síntesis microbial disminuye la producción de metano ya que parte de la MS degradada queda retenida en la masa microbial (Blümmel et al., 1997). Aunque en este trabajo no se evalúa el crecimiento microbial, se sugiere que un aumento en la fermentabilidad de la MS está asociada a una mayor síntesis de proteína microbial (Russell et al., 1992). En este estudio, la digestibilidad de la MS aumentó como consecuencia de la adición del trébol al kikuyo pero no al ryegrass, por lo cual se podría sugerir que la síntesis microbial aumentó para las mezclas de trébol con kikuyo pero no con ryegrass. Una menor producción de metano y gas como consecuencia de una mayor degradabilidad de la MS (energía) se daría siempre y cuando exista suficiente proteína en el medio de 


\section{VARGAS, PABÓNY CARULLA}

cultivo para el uso de esta energía adicional por los microorganismos. Se ha demostrado que existen relaciones óptimas entre energía y proteína que maximizan la síntesis microbial (Rusell et al., 1992), por lo cual se podría especular que la producción de gas y de metano no solo dependerían de la fermentabilidad de los carbohidratos sino que las relaciones energía:proteína serían también determinantes en este proceso.

\section{ADICIÓN DE LOTUS A LAS GRAMÍNEAS Y PRODUCCIÓNDEMETANO}

El aumento en la proporción de lotus disminuyó las emisiones totales de metano $(\mathrm{mL}) \sin$ importar la gramínea a la cual estuvo asociado (tabla IV). El Lotus uliginosus es una leguminosa con moderados niveles de taninos condensados (tabla I). La inclusión de leguminosas taníferas se ha relacionado con una disminución en la producción de metano tanto en estudios in vitro (Hess et al., 2008; Hess et al., 2006) como in vivo (Woodward et al., 2004; Woodward et al., 2001). Se han sugerido algunos mecanismos que podrían explicar el efecto de los taninos condensados en la producción de metano como es la reducción de la degradabilidad de la MS, Waghorn (2008) sugiere que los taninos condensados forman complejos indigeribles con algunos nutrientes de la dieta que evitan que se degraden en el rumen. Los taninos del lotus han sido relacionados con una disminución de la digestibilidad de la MS y la proteína (Chipatecua et al., 2007). La disminución en la digestibilidad del material fermentado ha sido atribuida además a la formación de complejos entre los taninos y las enzimas del hospedero y/o de los microorganismos del rumen resultando en la inactivación de los complejos enzimáticos encargadas de la hidrólisis de los nutrientes (Patra y Saxena, 2010). Los taninos condensados podrían tener efectos bacteriostáticos sobre algunas poblaciones ruminales, lo que podría resultar en una menor digestibilidad del material fermentado (Tavendale et al., 2005).
En síntesis, la disminución en la digestibilidad de los nutrientes en el rumen disminuye la producción de $\mathrm{H}_{2}$ y $\mathrm{CO}_{2}$ precursores de la síntesis de metano. La menor digestibilidad de la MS permitiría explicar los resultados observados en este trabajo.

El aumento en la inclusión de lotus disminuyó la producción de AGV y la proporción de acetato. Algunos autores han sugerido que los patrones de fermentación podrían explicar las diferencias en la producción de metano. Moss et al. (2000) sugieren que la producción de metano presenta una relación directa con las concentraciones de acetato pero inversa con las de propionato. La síntesis de acetato libera $\mathrm{H}_{2}$ mientras que la de propionato requiere $\mathrm{H}_{2}$ para su síntesis (Russell, 1998). Sin embargo, la disminución en la producción de metano debido a la modificación en el patrón de fermentación no fue evidente en este trabajo. Por otra parte, la inclusión de leguminosas con taninos condensados ha sido relacionada con un posible efecto bacteriostático o bactericida sobre algunas poblaciones ruminales. Tavendale et al. (2005) sugieren que los taninos condensados del lotus podrían tener efecto bacteriostático sobre algunas poblaciones metanogénicas. La disminución en la producción de metano por unidad de gas producido sugiere que el aumento en la inclusión de lotus disminuye la síntesis de metano.

\section{CONCLUSIONES}

Se encontró que el efecto de añadir una leguminosa (trébol o lotus) a una gramínea (kikuyo o ryegrass) sobre la producción de metano in vitro dependió de las especies mezcladas. Al adicionar trébol al kikuyo, la producción de metano disminuyó, pero no se observó este efecto con el ryegrass. Al aumentar la proporción de lotus en las mezclas disminuyó la producción total de metano independientemente de la gramínea con la que se mezcló. La presencia de una leguminosa tanífera disminuyó la concen- 


\section{PRODUCCIÓN DE METANO IN VITROEN MEZCLAS GRAMÍNEAS-LEGUMINOSAS}

tración de metano en el gas producido, sugiriendo un posible efecto sobre las poblaciones metanogénicas. El incremento en la proporción de leguminosas en la mezcla se relacionó con el aumento en la concentración de proteína presentándose una relación inversa con la producción de AGVs.

\section{BIBLIOGRAFÍA}

AOAC. 2005. Association of Official Agricultural Chemists. Official methods of analysis. Washington, D.C. USA.

Bentacourt, M. 2001. Efecto de la melaza, ácido fórmico y tiempo de fermentación sobre la ensilabilidad de la Leucaena leucocephala. Trabajo de Grado. Facultad de Agronomía. Universidad del Zulia. Maracaibo, Venezuela.

Beukes, P.C.; Gregorini, P.; Romera, A.J.; Levy, G. and Waghorn, G.C. 2009. Modelling the efficacy and profitability of mitigation strategies for reducing greenhouse gas emissions on pastoral dairy farms in New Zealand. $18^{\text {th }}$ World IMACS/MODSIM Congress. Cairns, Australia.

Blümmel, M. and Lebzien, P. 2001. Predicting ruminal microbial efficiencies of dairy ration by in vitro techniques. Livest Prod Sci, 68: 107-117.

Blümmel, M.; Makkar, H.P.S. and Becker, K. 1997. In vitro gas production: a technique revisited. $J$ Anim Physiol An N, 77: 24-34.

Carulla, J.E.; Kreuzer, M.; Machmüller, A. and Hess, H.D. 2005. Supplementation of Acacia mearnsii tannin decreases methanogenesis and urinary nitrogen in forage-fed sheep. Aust J Agr Res, 56: 961-970.

Castro, E.; Mojica, J.E.; León, J.M.; Pabón, M.L.; Carulla, J.E. y Cárdenas, E.A. 2008. Productividad de pasturas y producción de leche bovina bajo pastoreo de gramínea y gramínea + Lotus uliginosus en Mosquera, Colombia. Rev Med Vet Zoot, 55: 9-21.

Chipatecua, M.R.; Pabón, M.L.; Cárdenas, E.A. y Carulla, J.E. 2007. Efecto de la combinación de una leguminosa tanífera (Lotus uliginosus cv. Maku) con Pennisetum clandestinum, sobre la degradación in vitro de proteína y materia seca. Rev Colomb Cienc Pecu, 20: 40-48.

Gerber, P.J.; Steinfeld, H.; Henderson, B.; Mottet, A.; Opio, C.; Dijkman, J.; Falcucci, A. and Tempio, G. 2013. Tackling climate change through

\section{AGRADECIMIENTOS}

A Diana Parra por su colaboración en el desarrollo de los procedimientos de laboratorio de este experimento y al Ministerio de Agricultura y Desarrollo Rural por la financiación de este proyecto.

livestock - A global assessment of emissions and mitigation opportunities. Food and Agriculture Organization of the United Nations (FAO). Rome, Italy.

Goering, H.K. and Van Soest, P.J. 1970. Foragefiberanalysis (apparatus, reagents, procedures and some applications). Agricultural Handbook, no 379. ARS-USDE. Washington, DC.

Hess, H.D.; Tiemann, T.; Noto, F.; Carulla, J. and Kreuzer, M. 2006. Strategic use of tannins as means to limit methane emission from ruminant livestock. Int Congr Series, 1293: 164-167.

Hess, H.D.; Mera, M.L.; Tiemann, T.T.; Lascano, C.E. and Kreuzer, M. 2008. In vitro assessment of the suitability of replacing the low-tannin legume Vignaunguiculata with the tanniniferous legumes Leucaena leucocephala, Flemingia macrophylla or Calliandra calothyrsus in a tropical grass diet. Anim Feed Sci Tech, 147: 105-115.

Hess, H.D.; Monsalve, L.M.; Lascano, C.E.; Carulla, J.E.; Díaz, T.E. and Kreuzer, M. 2003. Supplementation of a tropical grass diet with forage legumes and Sapindus saponaria fruits: effects on in vitro ruminal nitrogen turnover and methanogenesis. Aust J Agr Res, 54: 703-713.

IPCC. 2013. Summary for Policymarkers. In: Stocker, TF., Qin, D., Plattner, GK., Tignor, M., Allen, SK., Boschung, J., Nauels, A., Xia, Y., Bex, V. and Midgley, P.M. (Eds). Climate Change 2013: The physical science basis. Contribution of Working Group I to the Fifth Assessment Report of the Intergovernmental Panel of Climate Change. Cambridge University Press. Cambridge. United Kingdom and New York, USA.

Johnson, K.A. and Johnson, D.E. 1995. Methane emissions from cattle. J Anim Sci, 73: 24832492.

Lee, J.M.; Woodward, S.L.; Waghorn, G.C. and 


\section{VARGAS, PABÓNYCARULLA}

Clark, D.A. 2004. Methane emissions by dairy cows fed increasing proportions of white clover (Trifolium repens) in pasture. Proc NZ Grassland Assoc, 66: 151-155.

Leng, R.A. 2011. The rumen- a fermentation vat or a series of organized structured microbial consortia: implications for the mitigation of enteric methane production by feed additives. Livest Res Rural Dev, 23: Article \#258. (12/03/2014).

López, S. 2005. In vitro and in situ techniques for estimating digestibility. In: Dijkstra, J.; Forbes, J.M. and France, J. (Eds.). Quantitative aspects of ruminant digestion and metabolism. CABI Publishing. $2^{\text {nd }} \mathrm{ed}$. Wallingford, UK.

Moss, A.; Jouany, J.P. and Newbold, J. 2000. Methane production by ruminants: its contribution to global warming. Ann Zootech, 29: 231253.

Niggli, U.; Fliebbach, A.; Hepperly, P. and Scialabba, N. 2009. Low greenhouse gas agriculture: Mitigation and adaptation potential of sustainable farming systems. FAO. Rev 2-2009.

Parra, D.M. y Avila, M.J. 2010. Determinación de los parámetros fisiológicos y dinámica ruminal de bovinos en condiciones de poli-túnel para evaluar emisiones de metano en trópico alto y bajo colombiano. Tesis para optar por el grado de Zootecnista. Programa de Zootecnia. Facultad de Ciencias Agropecuarias. Universidad de Cundinamarca. Fusagasugá, Colombia.

Patra, A.K. and Saxena, J. 2010. Review: A new perspective on the use of plant secondary metabolites to inhibit methanogenesis in the rumen. Phytochemistry, 71: 1198-1222.

Pell, A.N. and Scofield, P. 1993. Computerized monitoring of gas production to measure forage digestion in vitro. J Dairy Sci, 76: 1063-1073.

Russell, J.B. 1998. The importance of $\mathrm{pH}$ in the regulation of ruminal acetate propionate ratio and methane production in vitro. J Dairy Sci, 81: 3222-3230.

Russell, J.B.; O'Connor, J.D.; Fox, D.G.; Van Soest, P.J. and Sniffen, C.J. 1992. A net carbohydrate and protein system for evaluating cattle diets: I. Ruminal fermentation. J Anim Sci, 70: 35513561.

Stürm, C.D.; Tiemann, T.T.; Lascano, C.E.; Kreuzer, M. and Hess, H.D. 2007. Nutrient composition and in vitro ruminal fermentation of tropical legume mixtures with contrasting tannin contents. Anim Feed Sci Tech, 138: 29-46.

Tavendale, M.H.; Meagher, L.; Pacheco, D.; Walker, N.; Attwood, G.T. and Sivakumaran, S. 2005. Methane production from in vitro rumen incubations with Lotus pedunculatus and Medicago sativa, and effects of dextractable condensed tannin fractions on methanogenesis. Anim Feed Sci Tech, 123-124: 403-419.

Tekippe, J.A.; Tacoma, R.; Hristov, A.N.; Lee, C.; Oh, J.; Heyler, K.S.; Cassidy, T.W.; Varga, G.A. and Bravo, D. 2013. Effect of essential oils on ruminal fermentation and lactation performance of dairy cows. J Dairy Sci, 96: 7892-7903.

Terrill, T.H.; Rowan, A.M.; Douglas, G.B. and Barry, T.N. 1992. Determination of extractable and bound condensed tannin concentration in forage plants, protein concentrated meals and cereal grains. J Sci Food Agri, 58: 321-329.

Theodorou, M.K.; Williams, B.A.; Dhanoa, M.S.; McAllan, A.B. and France, J. 1994. A simple gas method using a pressure transducer to determine the fermentation kinetics of the ruminant feeds. Anim Feed Sci Tech, 48: 185-197.

Tiemann, T.T.; Lascano, C.E.; Wettstein, H.R.; Mayer, A.C.; Kreuzer, M. and Hess, H.D. 2008. Effect of the tropical tannin-rich shrub legumes Calliandra calothyrsus and Flemingia macrophylla on methane emission and nitrogen and energy balance in growing labs. Animal, 2: 790-799.

Van Soest, P. 1994. Nutritional ecology of the ruminant. $2^{\text {nd }}$ ed. Cornell University Press. USA. $271 \mathrm{pp}$.

Van Soest, P., Roberton, J. and Lewis, B. 1991. Methods for dietary fiber, neutral fiber and no starch polysaccharides in relation to nutrition. $J$ Dairy Sci, 74: 3583-3597.

Vargas, J.; Cárdenas, E.; Pabón, M. y Carulla, J. 2012. Emisión de metano entérico en rumiantes en pastoreo. Arch Zootec, 61: 51-66.

Vargas, J.J.; Cárdenas, E.A.; Mayorga, O.L.; Pabón, M.L. and Carulla, J.E. 2013. Changes in methane emission due to species, maturity and legume proportion in grass:legume mixtures incubated in vitro of Colombian highland forages. Proceedings of the $5^{\text {th }}$ International Conference on Greenhouse Gases and Animal Agriculture. Ed.: R. Dewhurst. Dublin, Ireland. June 23-26.

Waghorn, G. 2008. Beneficial and detrimental effects of dietary condensed tannins for 


\section{PRODUCCIÓN DE METANO IN VITROEN MEZCLAS GRAMÍNEAS-LEGUMINOSAS}

sustainable sheep and goat production-Progress and challenges. Anim Feed Sci Tech, 147: 116139.

Woodward, S.L.; Waghorn, G.C.; Ulyatt, M.J. and Lassey, K.R. 2001. Early indications that feeding Lotus will reduce methane emissions form ruminants. Proc New Zeal Soc An, 61: 23-26. Woodward, S.L.; Waghorn, G.C. and Laboyrie, P.G. 2004. Condensed tannins in birdsfoot trefoil (Lotus corniculatus) reduce methane emissions from dairy cows. Proc New Zeal Soc An, 64: 160-164.

Archivos de zootecnia vol. 63, núm. 243, p. 407. 